\title{
Prevalência de infecção chagásica em doadores de sangue do Hemocentro Regional de Iguatu, CE
}

\author{
Chagasic infection prevalence in blood donors for the \\ Hemocentro Regional de Iguatu
}

\author{
Ana Claudia de Menezes Sobreira', Francisca Vânia Barreto Aguiar Ferreira Gomes², \\ Marcos Antônio Martins da Silva² e Maria de Fátima Oliveira ${ }^{1}$
}

\begin{abstract}
Resumo Esse estudo tem como objetivo avaliar a prevalência de infecção pelo Trypanosoma cruzi em doadores de sangue do Hemocentro regional de Iguatu, CE, 1996-1997, usando os testes Ensaio Imunoenzimático (ELISA ) e Hemaglutinação Passiva Reversa (HPR). Dos 3.232 doadores analisados 61 (1,9\%) foram soropositivos para a infecção chagásica, onde o maior número de soropositividade foi encontrado no grupo de 41-50 anos, no entanto, o maior número de doadores que procuram o branco de sangue encontra-se na faixa etária de 18-30 anos. Do total de doadores analisados 2.991 (92,5\%) foram do sexo masculino e destes 57 $(1,9 \%)$ foram soropositivos. Com relação a procedência dos doadores observamos que $1.825(56,5 \%)$ foram procedentes da área rural. Os resultados mostram que o ELISA detectou 49 doadores com a infecção e por HPR apenas 38, mostrando portanto que a utilização de dois ou mais testes em bancos de sangue poderá prevenir a transmissão da doença de Chagas associada à transfusão.
\end{abstract}

Palavras-chaves: Doença de Chagas. Epidemiologia. Trypanosoma cruzi.

Abstract The objective of this study is to evaluate the frequency of Trypanosoma cruzi infection among blood donors at the Iguatu Regional Hemocenter, CE, 1996 - 1997, using the Enzyme-linked immunosorbent assay (ELISA) and hemagglutination passive reverse (HPR) tests. Of the 3,232 donors analyzed a total of 61 (1.9\%) were seropositive for chagasic infection. The greatest number of infected donors was found in the 41-50 year age group, while the majority of donors were in the 18-30 year age group. Of the total number of donors analyzed 2,991 (92.5\%) were men and $57(1.9 \%)$ of these were soropositive. In all 1,825 (56.5\%) of the donors were from a rural area. The results showed that the ELISA test detected 49 cases of infection, but HPR only 38 , thereby demonstrating that the use of two or more different tests by blood banks prevents transfusion associated Chagas' disease.

Key-words: Chagas' disease. Blood donors. Trypanosoma cruzi.

A doença de Chagas, infecção sistêmica de evolução essencialmente crônica, é causada pelo protozoário Trypanosoma cruzi. Essa infecção é endêmica em algumas regiões da América do Sul, sendo transmitida através do contato com as fezes do inseto vetor (triatomíneo) infectado e por outras vias secundárias tais como transfusão sangüínea e congênita. $O$ controle da transmissão vetorial foi realizado com sucesso em vários países do Cone Sul, sendo hoje a transfusão sangüínea a principal via de transmissão da infecção chagásica nesses países ${ }^{211}$. Entretanto, a doença de Chagas ainda hoje persiste como um sério problema de saúde pública após 90 anos de sua descoberta ${ }^{371114}$.

De acordo com dados descritos pela Organização Mundial de Saúde ${ }^{1718}$ a doença de Chagas na América Latina atinge entre 18-20 milhões de pessoas e mais de 90 milhões, que habitam as zonas endêmicas, estão sob risco de se infectar. No Brasil, a prevalência é de 5 milhões de pessoas infectadas com maior taxa no Estado de Goiás e a incidência é de 20.000 mil novos casos por ano ${ }^{11} \mathrm{e}$ anualmente mais de 50.000 pessoas morrem por ano de doença de Chagas ${ }^{17}$. A soroprevalência da doença de Chagas em doadores de sangue é de 51\% em Santa Cruz (Bolívia), 5,6\% em Buenos Aires

\footnotetext{
1-Departamento de Análises Clínicas e Toxicológicas da Faculdade de Farmácia, Odontologia e Enfermagem da Universidade Federal do Ceará (FFOE/UFC). 2-Hemocentro do Ceará (HEMOCE) Fortaleza, CE.

Endereço para correspondência: Dra. Maria de Fátima Oliveira. Av. Marechal Fiúza de Castro 435/71, Bloco 1, Jd Bonfiglioli, 05596-000 São Paulo, SP. e-mail: fatimaufc@ hotmail.com

Recebido para publicação em 29/04/99.
} 
(Argentina), 0,2 a 12,4\% no Chile, 0,7\% no Brasil, e $5,3 \%$ no Paraguai $^{5}{ }^{16}$. Silva et al $^{12}$ realizaram um estudo nos bancos de sangue do Estado do Ceará no período de 1996 a 1997, onde foram atendidos 34.943 doadores dos quais $377(1,1 \%)$ apresentavam soropositividade para infecção chagásica.
Devido a falta de informações divulgadas sobre a infecção por $T$. cruzi e por ser o Ceará uma região endêmica para esta enfermidade, consideramos importante investigar a prevalência desta infecção em doadores de sangue do Hemocentro Regional de Iguatu, Ceará.

\section{MATERIAL E MÉTODOS}

Esse trabalho consistiu em consultar os arquivos de todos os doadores de sangue que tiveram sorologia para infeção chagásica, no período de janeiro de 1996 a abril de 1997, no Hemocentro Regional de Iguatu-CE. Neste estudo foram incluídos os doadores de retorno pois os mesmos tem seu valor estatístico visto que existe a possibilidade de serem soropositivos em uma terceira ou quarta doação, já que se trata de uma região endêmica.

O Hemocentro Regional de Iguatu abrange toda a Região Centro-Sul do Ceará, numa área de $27.618,9 \mathrm{Km}^{2}$, com uma população de 574.806 habitantes incluindo os seus 23 municípios (IBGE, censo 96). O Hemocentro
Regional de Iguatu iníciou suas atividades em setembro de 1993. Os doadores foram agrupados por faixa etária em 4 grupos: 1) entre 18 - 30 anos; 2) entre 31-40 anos; 3) entre 41- 50 anos e 4) entre 51- 60.

O Hemocentro realiza a triagem sorológica para a doença de Chagas empregando os métodos de Hemaglutinação Passiva Reversa (HPR) e Ensaio Imunoenzimático $(E L I S A)^{456}$. No caso do resultado ser positivo em apenas um dos testes a bolsa de sangue é descartada, mas o resultado só é liberado como positivo quando uma segunda amostra é colhida e o exame é repetido. Neste caso os doadores que retornam para repetir a sorologia não foram incluído neste estudo.

\section{RESULTADOS}

Foram atendidos no Hemocentro de Iguatu, no período de janeiro de 96 a abril de 1997, 3.232 doadores dos quais 61 (1,9\%) foram soropositivos para infecção chagásica (Tabela 1). Do total de doadores analisados 2.991

Tabela 1 - Distribuição dos doadores soropositivos para infecção chagásica do Hemocentro Regional de Iguatu - Ceará, 1996- 1997, segundo a faixa etária.

\begin{tabular}{|c|c|c|c|c|c|c|c|}
\hline \multirow[t]{2}{*}{ Doadores } & \multicolumn{5}{|c|}{ Grupo etário (anos ) } & \multicolumn{2}{|c|}{ Total } \\
\hline & $18-30$ & $31-40$ & $41-50$ & $51-60$ & $S / D$ & № & $\%$ \\
\hline Reagentes & 11 & 16 & 23 & 11 & - & 61 & 1,9 \\
\hline Total & 1.298 & 1.004 & 671 & 253 & 6 & 3.232 & 100,0 \\
\hline
\end{tabular}

$\mathrm{S} / \mathrm{D}$ = sem declaração

$(92,5 \%)$ foram do sexo masculino e destes $57(1,9 \%)$ foram soropositivos (Tabela 2). Os doadores que mais

procuram os bancos de sangue encontram-se na faixa etária de 18 a 30 anos, embora a maior incidência de doadores

\begin{tabular}{|c|c|c|c|c|}
\hline \multirow[t]{2}{*}{ Sexo } & \multicolumn{2}{|c|}{ Total } & \multicolumn{2}{|c|}{ Positivo } \\
\hline & $\mathrm{n}^{\circ}$ & $\%$ & $\mathrm{n}^{\circ}$ & $\%$ \\
\hline Masculino & 2.991 & 92,5 & 57 & 1,9 \\
\hline Feminino & 241 & 7,5 & 4 & 1,7 \\
\hline Total & 3.232 & 100 & 61 & 3,6 \\
\hline
\end{tabular}

soropositivos para a infecção chagásica encontre-se na faixa de 41 a 50 anos com 23 (37,7\%) (Tabela 1).

Segundo a distribuição das profissões entre os doadores soropositivos para infecção chagásica, observamos que $62,3 \%$ foram agricultores, $6,6 \%$ pedreiros, $4,9 \%$ do lar e $3,3 \%$ comerciantes. Com relação à procedência dos doadores observamos que $1.825(56,5 \%)$ foram procedentes da área rural. A distribuição dos doadores soropositivos foram provenientes dos municípios de Iguatu com $13(21,1 \%), 12(19,7 \%)$ de Icó, 07 (11,5\%) de Cedro e $04(6,6 \%)$ de Quixelô, entre outros municípios com menor prevalência, mas a maioria $33(1,8 \%)$ provinham da zona rural (Tabela 3$)$. De acordo com os resultados dos testes empregados, observamos que $26(42,6 \%)$ foram positivos para (ELISA e HPR), 23 (37,7\%) foram positivos somente para ELISA e $12(19,7 \%)$ somente para HPR (Tabela 4). Dos 61 doadores soropositivos 39 $(63,9 \%)$ já haviam doado sangue anteriormente e $22(36,1 \%)$ nunca haviam doado. Vale salientar que $45(73,7 \%)$ doadores conhecem o barbeiro, o inseto transmissor da infecção chagásica. 
Tabela 3 - Prevalência de soropositividade para doadores de sangue do Hemocentro Regional de Iguatu-Ceará, 1996 -1997, segundo a procedência.

\begin{tabular}{lcrrrr}
\hline Procedência & \multicolumn{2}{c}{ Total } & & \multicolumn{2}{c}{ Positivos } \\
\cline { 2 - 3 } \cline { 5 - 6 } & № & № & 28 & 0,9 \\
\hline Urbana & 1.407 & 43,5 & 33 & 1,8 \\
Rural & 1.825 & 56,5 & 61 & 2,7 \\
\hline Total & 3.232 & 100,0 & 28 & \\
\hline
\end{tabular}

\begin{tabular}{lcc}
$\begin{array}{l}\text { Tabela } \\
\text { testes ELISA e HPR dos doadores do Hemocentro Regional de Iguatu-Ceará, 1996-1997. }\end{array}$ \\
\hline Testes & № de doadores positivos & $\%$ \\
\hline ELISA & 23 & 37,7 \\
HPR & 12 & 19,7 \\
ELISA + HRP & 26 & 42,6 \\
\hline Total & 61 & 100,0 \\
\hline
\end{tabular}

\section{DISCUSSÃO}

Apesar das medidas sanitárias de erradicação do inseto transmissor (barbeiro) e da ampliação do sistema de hemocentros regionais terem apresentado impacto positivo na diminuição da incidência da doença de Chagas, o número de pessoas infectadas ainda é preocupante.

No presente trabalho, a freqüência de sorologia positiva para a infecção chagásica entre os doadores do Hemocentro de Iguatu, no período de janeiro de 96 a abril de1997, foi relativamente alta (1,9\%) considerando que se trata de um grupo de indivíduos aparentemente sãos e num estado de saúde que lhe permite doar sangue (Tabela 1 ). Silva et $\mathrm{al}^{12}$ realizaram um estudo nos bancos de sangue do Estado do Ceará no período de 1996 a 1997, onde foram atendidos 34.943 doadores dos quais $377(1,1 \%)$ apresentavam soropositividade para infecção chagásica. A prevalência de $(1,9 \%)$ de doadores soropositivos, encontrada por nós, foi superior (1\%) à encontrada por Souza et $\mathrm{al}^{14}$, em 1989/90, para doadores de sangue de 585 municípios brasileiros e inferior a prevalência encontrada $(3,5 \%)$ por Zicker et al ${ }^{19}$, em 1988/89, para doadores de seis bancos de sangue de Goiânia, GO.

Nesse estudo, observamos que os doadores que mais procuram os bancos de sangue encontram-se na faixa etária de 18 a 30 anos, embora a maior frequência de doadores soropositivos para a infecção chagásica encontre-se na faixa de 41 a 50 anos com 23 (37,7\%). Segundo a Fundação Nacional de Saúde (FNS/1998), a transmissão vetorial da doença de Chagas no Estado do Ceará estava controlada. No entanto, a falta de inseticida e pessoal no programa de combate ao vetor em 1998 no Ceará provocou um aumento do número de barbeiros em alguns municípios. Para ter-se uma idéia, em abril de 2000, foi notificada a presença de um foco de barbeiros no município de Jaguaruana, onde foram capturados 600 barbeiros, e $52 \%$ de 300 examinados estavam infectados com o Trypanosoma cruzi (comunicado no jornal local, O POVO).

Estudo realizado por Zicker et $\mathrm{al}^{19}$, com 1.358 primodoadores de seis bancos de sangue de Goiâna, no período de1988/1989, demonstrou maior prevalência de infecção chagásica, na faixa etária de 36 a 45 anos. Contreras e col ${ }^{1}$ encontraram maior prevalência de infecção em indivíduos jovens em Jalisco, México. Já no estudo realizado por Sapino ${ }^{10}$, no Hospital Geral de Agudos em Mar Del Plata, Argentina, a média de idade foi de 45 anos.

No que diz respeito ao sexo, observamos predominância do sexo masculino com $92,5 \%$ dos doadores e destes 57 (1,9\%) foram soropositivos. Nossos resultados são divergentes do estudo de Contreras et $\mathrm{al}^{1}$, realizados em doadores de JaliscoMéxico, que mostraram uma prevalência de 1,3\% para o sexo masculino e $1,6 \%$ para o feminino. Segundo dados da FNS/1996, a doença de Chagas afeta indistintamente homens e mulheres.

Dos 61 doadores soropositivos 33 (54,1\%) eram agricultores de atividade exclusivamente rural, tendo provavelmente contraido a infecção através do inseto transmissor. Entretanto, devemos considerar que grande parte dos indivíduos de zona urbana ali chegaram em busca de trabalho, fugindo da seca, mas são também indivíduos provenientes de zona rural. Esses dados estão de acordo com os resultados demonstrados por Sapino et $\mathrm{al}^{10}$, onde $76 \%$ dos doadores soropositivos para Chagas eram nativos de zona rural mas habitavam a zona urbana ${ }^{8}$.

Baseado nos métodos de triagem sorológicas para infecção chagásica, no Hemocentro de Iguatu sugerimos a inclusão de um terceiro teste nos bancos de sangue visto que $23(37,7 \%)$ foram positivos somente para ELISA e $12(19,7 \%)$ para HPR e 26 (42,6\%) em ambos. Segundo Souza et $\mathrm{al}^{14}, 55,3 \%$ dos serviços 
hemoterápicos do Brasil no período de 1989/90 empregavam somente um teste para Chagas. Em São Paulo, $92,8 \%$ dos serviços realizavam dois ou mais testes para triagem da doença de Chagas ${ }^{9} 141516$.

Outro dado relevante é que, $39(63,9 \%)$ dos indivíduos já haviam doado sangue antes do funcionamento do Hemocentro (setembro de 93), com risco de transmissão da enfermidade de Chagas já que não eram realizados os testes sorológicos. É possível que grande parte dessas doações tenham ocorrido em caráter de urgência, determinando-se apenas o grupo sangüíneo/ fator $\mathrm{Rh}$, procedimento bastante comum na região antes do funcionamento do Hemocentro. No estudo realizado por Sapino e $\mathrm{col}^{10}, 31$ (94\%) dos 33 doadores soropositivos haviam doado sangue em outras oportunidades e nunca foram notificados de sua condição. Em nossa investigação, observamos que 45 $(73,8 \%)$ dos doadores soropositivos conheciam o transmissor, denominado pelos moradores da região (Iguatu-CE) de procotó, mas acreditamos que esses indivíduos desconhecem o potencial patogênico desse inseto. Sapino et $\mathrm{al}^{10}$, relataram em seu estudo que $78,8 \%$ dos doadores conheciam o barbeiro mas não conheciam a enfermidade transmitida por eles.

\section{REFERÊNCIAS BILIOGRÁFICAS}

1. Contreras FT, Kasten FL, Gutierrez MMS, Gutierrez RM. Prevalencia de infección a Trypanossoma cruzi en donadores de sangre en el Estado de Jalisco, Mexico. Revista da Sociedade Brasileira de Medicina Tropical 26:89-92, 1993.

2. Dias JCP. Chagas disease and blood transfusion in endemic areas In:Wendel S, Brener Z, Camargo ME, Rassi A. (eds). Chagas disease (american trypanosomiasis): its impact on transfusion and clinical medicine. International Society of Blood Transfusion Brazil, São Paulo, 1992

3. Dias JCP. Epidemiology of Chagas disease. In: Wendel S, Brener Z, Camargo ME, Rassi A (eds) Chagas disease (american trypanosomiasis). Its impact on transfusion and clinical medicine. International Society of Blood Transfusion Brazil, São Paulo ,1992.

4. Dias JCP, Schofield CJ. Controle da transmissão transfusional da doença de Chagas na iniciativa do Cone Sul. Revista da Sociedade Brasileira de Medicina Tropical 31:373-383, 1998.

5 Ferreira AW, Belem ZR, Moura MEG, Camargo ME. Aspectos da padronização de testes sorológicos para a doença de Chagas. Um teste imunoenzimático para a triagem de doadores de sangue. Revista do Instituto de Medicina Tropical de São Paulo, 33: 123-128, 1991.

6. Ferreira A W. Diagnostic testes for Chagas disease. Serological diagnosis. Tests for Chagas disease serodiagnosis; A review. In: Wendel S, Brener Z, Camargo ME, Rassi A (eds) Chagas diseases (American Trypanosomiasis): Its impact on transfusion and clinical medicine. International Society of Blood Transfusion Brazil,São Paulo, p.179-194, 1992.

7. Leiby DAEJ, Read BA, Lenes AJ, Yund RJ, Stumpf LV \& Kirchhoff RY D. Seroepidemiology of Trypanosoma cruzi, etiologic agent of Chagas' disease, in U.S. blood donors. Journal infectious Diseases 176:1047-1052, 1997.

8. Lorca M, Reyes V, Child R, Marisol D, Atias A. Enfermedad de Chagas y transfusión sanguínea en el area occidente de slud de Santiago: Algunos aspectos epidemiologicos importantes del donante chagásico Boletin Hospital San Juan de Dios 37 :72-76, 1990.
9. Reiche EMV, Jankevicius IV. Avaliação de métodos alternativos para o diagnóstico laboratorial confirmatório da doença de Chagas. Revista Brasileira de Análises Clínicas 29:29-40, 1997.

10. Sapino R V, Janin CE, Araújo JE. Etudio de indivíduos com sorologia positiva para Chagas detectados en el Banco de Sangre del Hospital General de Agudos, Mar Del Plata. CM Publicación Medica, Mar Del Plata 6: 13-21, 1993.

11. Schmunis GA. Trypanosoma cruzi, the etiologic agent of Chagas' disease: status in the blood supply in endemic and nonendemic countries. Transfusion .31:547-557,1991

12. - Silva VC, Figueiredo AA, Queiroz JAN, Andrade FB Análise da prevalência de anticorpos anti- $T$. cruzi em doadores de sangue do Centro de Hematologia e Hemoterapia do Ceará (HEMOCE).In: Resumos do XVII Encontro Universitário de Iniciação à Pesquisa, Fortaleza, p. 368,1998.

13. Souza HM, Wanderley DM, Brener S. Hemoterapia e doença de Chagas transfusional no Brasil. Boletin de la Oficina Sanitaria Panamericana. 116:406-418, 1994.

14. Souza M, Bordini JO. Strategies for prevention of transfusion associated Chagas disease. Transfusion Medicine Reviews 10:161-170, 1996.

15. Wanderley DMV, Gonzales TT, Pereira MSCA. Controle da hemoterapia e da doença de Chagas transfusional: 1988 e 1990. Revista Saúde Pública 27:430-435, 1993.

16. Wendel S, Gonzaga AL. Chagas' disease and blood transfusion: a new world problem? Vox Sang 64: 1-12,1993.

17. World Health Organization. Control of Chagas Disease. WHO Technical Report Series, 811, Geneva, p. 95, 1991.

18. World Health Organization G. Twelfth programme report of the UNDp/ World Bank/WHO. Special Programme for Research and Training in Tropical Diseases (TDR). WHO, Geneve, 1995.

19. Zicker F, Marteli CMT, Andrade ALSS, Silva SA. Trends of T. cruzi infection based on data from blood bank screening. Revista do Instituto Medicina Tropical de São Paulo.32:132-137, 1990. 